\title{
Formulation and Evaluation of Water / Oil Pickering Emulsion Stabilized by Magnesium Oxide Particles Containing Paracetamol in the Internal Phase
}

\author{
Sidy Mouhamed Dieng ${ }^{1,2 *}$, Mamadou Soumboundou ${ }^{1}$, Papa Mady SY ${ }^{1}$, Thierno Mohamed \\ Wane $^{1}$, Alphonse Rodrigue Djiboune ${ }^{1}$, Louis Augustin Diaga Diouf ${ }^{1}$, Gora Mbaye ${ }^{1}$, Oumar \\ Thioune $^{2}$, Mounibé Diarra ${ }^{1}$ \\ ${ }^{1}$ Laboratory of Pharmaceutical Physics and Biophysics, Faculty of Medicine, Pharmacy and Odontology, \\ Cheikh Anta Diop University (UCAD), Dakar, Sénégal \\ ${ }^{2}$ Laboratory of galenic pharmacy, biopharmacie and pharmaceutical legislation, Faculty of Medicine, \\ Pharmacy and Odontology, Cheikh Anta Diop University (UCAD), Dakar, Sénégal
}

*Corresponding Author: Sidy Mouhamed Dieng, Laboratory of galenic pharmacy, biopharmacie and pharmaceutical legislation, Faculty of Medicine, Pharmacy and Odontology, Cheikh Anta Diop University (UCAD), Dakar, Sénégal

\begin{abstract}
Pickering emulsions are surfactant-free emulsions, stabilized by colloidal particles. These systems are experiencing renewed interest on the one hand, because it is preferable to limit the use of synthetic surfactants for ecological reasons, and on the other hand, because the functionalization of particles has undergone recent advances.

It is possible to make very simple calibrated emulsions of controlled size, exploiting a phenomenon called "limited coalescence".

We have formulated and characterized Pickering water type emulsions in oil stabilized by magnesium oxide particles and containing paracetamol in the internal phase. Bancroft's rules served as a model for the formulation. The emulsification was done by progressive addition of a dispersed aqueous phase in a dispersing oily phase using a turbo rotor-stator mixer. The stability of these emulsions has been studied using several parameters (droplet size, $\mathrm{pH}$, viscosity, conductivity...) and quantitative analysis of active principles by $U V$ visible spectrophotometry.
\end{abstract}

The dye test and conductivity measurement confirmed the E/H nature of these emulsions. Droplet size, PH, and viscosity were influenced by the quantities of magnesium oxide particles and the active ingredients used.

The quantitative analysis of paracetamol confirmed its presence in the aqueous phase.

The results showed that we were able to develop a stable Pickering type E/H emulsion with magnesium oxide particles. In addition, we were able to incorporate paracetamol into the dispersed phase.

Keywords: émulsion-Pickering-MgO-paracétamol

\section{INTRODUCTION}

Emulsions are dispersed metastable systems consisting of at least two non-miscible liquids and one amphiphilic agent. One of the liquids is dispersed in the second in the form of small spherical drops, the size of which varies according to the conditions of 0.1 to a few tens of micrometers [1.2]. The system thus created does not correspond to a thermodynamically stable state, the most stable condition would be the macroscopic separation of the two fluids.

Emulsions are widely produced and used in the industry. They are also food products such as milk, butter, mayonnaise, vinaigrettes, as well as cosmetic or pharmaceutical products to be applied on the skin such as creams or ointments. At the industrial scale, the emulsions are used for road covering or sealing of buildings (mastic). In all areas, most traditional formulations are challenged to meet new requirements related to environmental protection, user safety, ease of implementation and cost constraints. We are therefore moving towards the phasing out of organic solvents and synthetic surfactants, both of which are considered harmful to the environment [3.4]. 
Pickering and Ramsden [1.2] demonstrated at the beginning of the last century the feasibility of surfactant-free emulsions in the presence of solid particles. These emulsions are called "Pickering emulsions". This concept of emulsions stabilized by solid particles is experiencing renewed interest today because of the many advantages it presents good stability, protection of the environment, the safety of users, varieties of particles etc [5-14].

For a short time, the potential for the application of particle-stabilized emulsions has been considered in the pharmaceutical industry [15-19].

In addition, one of the main advantages of Pickering emulsions is that they are more stable than other types of emulsions. The adsorption of solid particles at the oil-water interface is strong and irreversible. This leads to the formation of a dense film thus creating a barrier around the droplets giving them a high resistance to coalescence. The particle adsorption or desorption energy:

$$
\Delta \mathrm{E}=\gamma_{\mathrm{o} / \mathrm{w}} \pi \mathrm{r}^{2}(1 \pm \cos \theta)^{2}
$$

( $\mathrm{r}$ is particle radius, $\gamma \mathrm{o} / \mathrm{w}$ is the oil-water interfacial tension and $\theta$ is the contact angle) is mainly related to their ability to be partially wetted by the two phases of the emulsion [4]. This wetting of the particles is characterized by an angle of contact between the aqueous phase, the oil phase, and the solid particles, measured on the side of the aqueous phase. Thus, the particles having a contact angle of less than $90^{\circ}$ are usually called hydrophilic and preferably stabilize the $\mathrm{O} / \mathrm{W}$ type emulsions whereas those whose contact angle is less than $90^{\circ}$ are called hydrophobic and are used to stabilize $\mathrm{W} / \mathrm{O}$ type emulsions $[4,7]$. This type of formulation can be a potential system for encapsulating active principles, allowing the controlled and targeted release of the asset from the internal phase. However, this type of emulsion is not yet marketed. There are numerous studies on the formulation and physicochemical properties of solid particle stabilized emulsions [1-29]. To date studies with the incorporation of an active principle have been very little described in the literature.

On the fundamental level, emulsions pose questions relating to their preparation (emulsification), their lifespan (mechanisms and kinetics of destruction), their flow properties (rheology, an elasticity of concentrated emulsions), etc. [7.13]. These questions were addressed in the presence of surfactants or proteins but rarely in the presence of solid particles.

In this study, we are interested in the formulation and evaluation of a Pickering emulsion stabilized by magnesium oxide particles. From this first formulation, we chose the most stable emulsions in order to incorporate paracetamol into the internal aqueous phase. Some parameters such as droplet size, viscosity, $\mathrm{pH}$, coverage rate and ability to encapsulate have been widely studied and discussed in this work.

\section{Material et Methods}

\subsection{Material}

The following equipment were used in this study: a rotor stator (RAYNIERIE), an optical microscope (ZEISS), an optical microscope (BBT KRAUSS), an CG820 pH meter (SCHOTT Gerate ${ }^{\circledR}$ ), an conductimeter (CG854 SCHOTT Gerate $\left({ }^{\circ}\right)$ an viscometer ( BROOKFIELD), an UV-visible spectrophotometer (UV Mini - 1240).

\subsection{Reagents}

The oily phase used throughout this study is a mixture of Hojiblanca ${ }^{\circledR}$ extra virgin olive oil from the market consisting mainly of unsaturated mono fatty acid, poly unsaturated and saturated fatty acid and Vaseline officinale. The particles used for stabilization are magnesium oxide (MgO) NORMAPUR ( lot no71329 from the RHONE-POULENC laboratories. It is a white powder of molecular weight (40.31 $\mathrm{g} / \mathrm{mol}$ ), soluble in $\mathrm{H}_{2} \mathrm{O}$ and insoluble in $\mathrm{HCl}$. The aqueous phase used is distilled water. The active ingredient used is paracetamol (N-acetyl-para-nitrophenol) or Hydroxy-1-acetamido-4-benzene (NAPAP) GSK Batch No RI0081. Various other ingrediens were used during the various stages of these experimental studies: methylene blue (Kuhlmann), Red Sudan III, ethanol (Scharlau ET0005).

\subsection{Méthods}

\subsubsection{Pickering Emulsion Formulation}

During the formulation, the meaning of the emulsion formed is one of the most important properties and characteristics. The formulator has always been confronted with the problem of predicting the type of emulsion formed when a water-oil-particle system is mixed and agitated. 
The Bancroft rule, which states that the type of emulsion depends on the medium in which the particles are initially introduced, has served as a model for the preparation of our formulations

- Preparation of the dispersing oily phase, in Vaseline, magnesium oxide is gradually added by grinding to homogenization.

- Preparation of dispersed aqueous phase, dissolves the amount of paracetamol to be incorporated into $30 \mathrm{ml}$ of distilled water. It is homogenized using a magnetic stirrer at $1000 \mathrm{rpm}$ for one minute.

- Emulsification

In the previously prepared suspension, the aqueous phase is gradually added followed by the fragmentation of the water droplets using the mixer. Then the final mixture is homogenized vigorously for 1 minute at $1680 \mathrm{rpm}$. The total time of preparation of the emulsion is 5 minutes. The preparation of all the emulsions of this work was carried out under the same operating conditions (agitation speed, agitation time, type of agitator, temperature).

\subsubsection{Characterization Of Emulsions}

- Macroscopic examination, The emulsions are left at rest away from light and an elevation of temperature in conical tubes of $50 \mathrm{ml}$ with screw-on lids. This visual inspection makes it possible to highlight certain phenomena of instability such as sedimentation, flocculation and coalescence.

- Determination of the direction of the emulsions, carried out by measurement of conductivity and a dye test. The principle of conductivity measurement is based on the measurement of the electrical resistance of the solution. In a $50 \mathrm{ml}$ conical tube with a screw cover containing the emulsion, the Conductometric cell is introduced. The conductive cell is plunged to the level of the emulsified phase for sedimentation tubes. In the presence of a conductive solution the needle of the galvanometer deviates towards higher values. The dye test principle is based on the determination of the water solubility or liposolubility of the resulting emulsion. In two beakers, place a few millilitres of the emulsion to be tested. In one of the beakers, add a drop of methylene blue, mix and in the other beaker sprinkle a few grams of Red Sudan (Sudan III) and mix.

- PH of the emulsions, the principle is based on the measurement of the potential between two electrodes dipping in a solution rich in $\mathrm{H}+$ ions. After calibrating the $\mathrm{pH}$ meter, the combined electrode is soaked in a $50 \mathrm{ml}$ conical tube with screw cover containing the preparation. As with conductivity, it is necessary to ensure that the electrodes are dipped to the emulsified phase level for sedimentation tubes. The reading time is set at 3 minutes after the electrode was introduced.

- Viscosity of the emulsions, the principle of measuring the viscosity retained by Brookfield is based on the application of a movement force to a product by rotating at fixed speed, a fixed-size mobile. The resistance of the product to the rotational movement of the mobile is recorded using an internal spiral spring and converted to a viscometric unit. In order to expand measurable viscosity ranges, several mobiles, speeds and spring types were used.

\section{- Coverage rate}

It translates the percentage of occupancy of the droplet surface formed by stabilizing particles. It can be determined by the equation:

$$
\mathrm{C}=\frac{\mathrm{m}_{\mathrm{p}} \mathrm{D}}{4 \mathrm{C}_{\mathrm{p}} \mathrm{d}_{\mathrm{p}} \mathrm{V}_{\mathrm{p}}}
$$

$\mathrm{m}_{\mathrm{p}}=$ particle mass, $\mathrm{D}=$ droplet size, $\mathrm{C}_{\mathrm{p}}=$ Particle density, $\mathrm{d}_{\mathrm{p}}=$ Particle diameter, $\mathrm{V}_{\mathrm{p}}=$ Volume of dispersed phase

\subsection{Encapsulation Efficiency (E.E)}

Destabilization and extraction of Paracetamol: destabilisation tubes were carried in the oven at $37{ }^{\circ} \mathrm{C}$ for one (01) hour until liquefaction, then centrifuge at $3500 \mathrm{rpm}$ for 20 minutes, the aqueous phase is extracted in Using a $05 \mathrm{ml}$ syringe. Then a second centrifugation of water is carried out at $3500 \mathrm{rpm}$ for one minute for purification.

Destabilization and extraction of Paracetamol: destabilization tubes were carried in the oven at $37{ }^{\circ} \mathrm{C}$ for one (01) hour until liquefaction, then centrifuge at $3500 \mathrm{rpm}$ for 20 minutes, the aqueous phase is extracted in Using a $05 \mathrm{ml}$ syringe. Then a second centrifugation of water is carried out at $3500 \mathrm{rpm}$ for one minute for purification. 


\section{Dosage}

A UV-visible spectrophotometer has been used for dosing. The operation obeys the Beer-Lambert law, which stipulates that at a given wavelength, the absorbance of a solution is proportional to its concentration and the wavelength of the optical path following the relationship :

The equation of the following line $(\mathrm{y}=\mathrm{a}+\mathrm{bX})$ allowed us to determine the concentrations of paracetamol $\mathrm{y}=0,3736 \mathrm{X}+0.0966$ with $\mathrm{R}=0.9997$.

\section{RESULTS AND DISCUSSION}

The study of physicochemical and analytical parameters of the various formulated emulsions stored in the dark at $25^{\circ} \mathrm{C}$ during the 28 days of monitoring ; allowed us to follow the evolution of the formulations as a function of time.

\subsection{Bottle Test}

The emulsions obtained are beige to yellow, homogeneous. The emulsions are all stable, better stability was observed with the emulsions containing $3 \mathrm{~g}$ of magnesium oxide.

In Table I and Figure 2 we have shown respectively the proportions used in the formulation and appearance of the prepared emulsions.

Table1. Proportions of formulations

\begin{tabular}{|l|c|c|c|c|c|c|c|c|}
\hline Tubes & T1 & T2 & T3 & T4 & T'1 & T'2 & T'3 & T'4 \\
\hline Holive oil $\{$ ml $)$ & 30 & 30 & 30 & 30 & 30 & 30 & 30 & 30 \\
\hline Distilled water $\{$ ml $)$ & 30 & 30 & 30 & 30 & 30 & 30 & 30 & 30 \\
\hline MgO $\{\mathbf{g})$ & 2 & 2 & 2 & 2 & 3 & 3 & 3 & 3 \\
\hline Vaseline $\{\mathbf{g})$ & 30 & 30 & 30 & 30 & 30 & 30 & 30 & 30 \\
\hline Paracétamol $\{\mathbf{g})$ & 0,0 & 0,125 & 0,250 & 0,500 & 0,0 & 0,125 & 0,250 & 0,500 \\
\hline
\end{tabular}

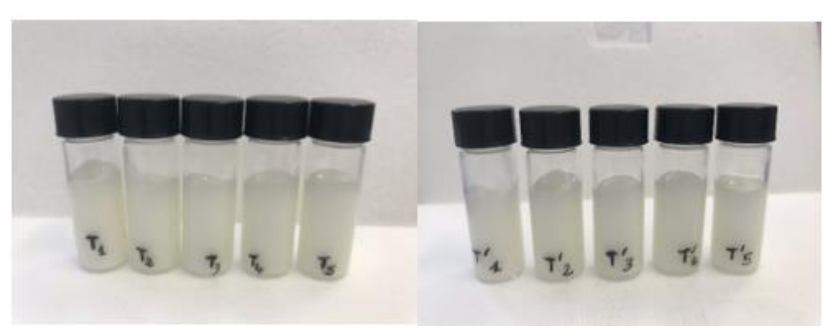

Figure2. Appearance of the tubes at the 28th day of conservation

Determining the direction of the emulsions : The dye tests carried out each week during the 28 days of monitoring showed us emulsions with aqueous droplets of heterogeneous sizes stained in blue by methylene blue and a dispersing phase colored red by red Sudan. The determination of the direction of our emulsions by the measurement of the conductivity on the following days: $j 1, j 7, j 14, j 21, j 28$, gave zero conductivities.

\subsection{Droplet size}

The droplet sizes are shown in the following figures 3 .
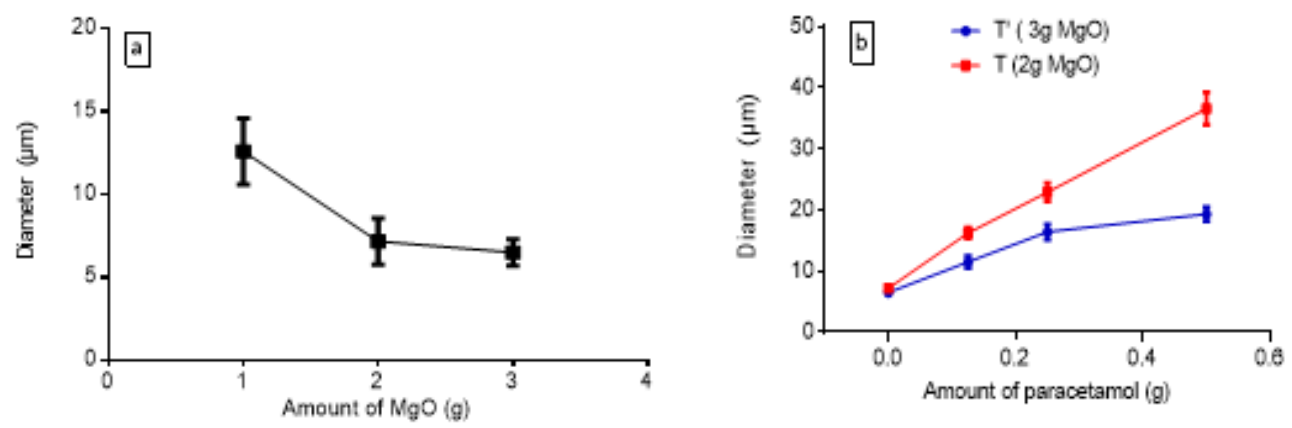

Figure3. droplet size in micrometer: (a) depending on the amount of magnesium oxide $(\mathrm{MgO}),(\mathrm{b})$ depending on the amount of paracetamol. 
Macroscopic examination shows no phenomenon of instability or destabilization of the formulated emulsions.

The size of the droplets plays an important role in the stability of the emulsions. This is one of the variables that influence the sedimentation rate described by the Stokes law.

$$
v=\frac{2 r^{2} g\left(D_{1}-D_{2}\right)}{9 \mu}
$$

$v$ sedimentation rate, $\mathrm{r}=$ droplet radius, $\mathrm{g}=$ acceleration due to gravity earth, $\mathrm{D} 1 ; \mathrm{D} 2=$ the respective densities of the dispersed phase and the continuous phase, $\mu=$ the viscosity of the continuous phase. The quantities in particle affect the nature of the droplets. The more particles there are, the more the droplets are fine. However, the size of the droplets increases with the amount of paracetamol introduced into the preparation. Samples containing fewer particles have a larger average diameter than samples containing a larger amount of particles, as show in figure 4.

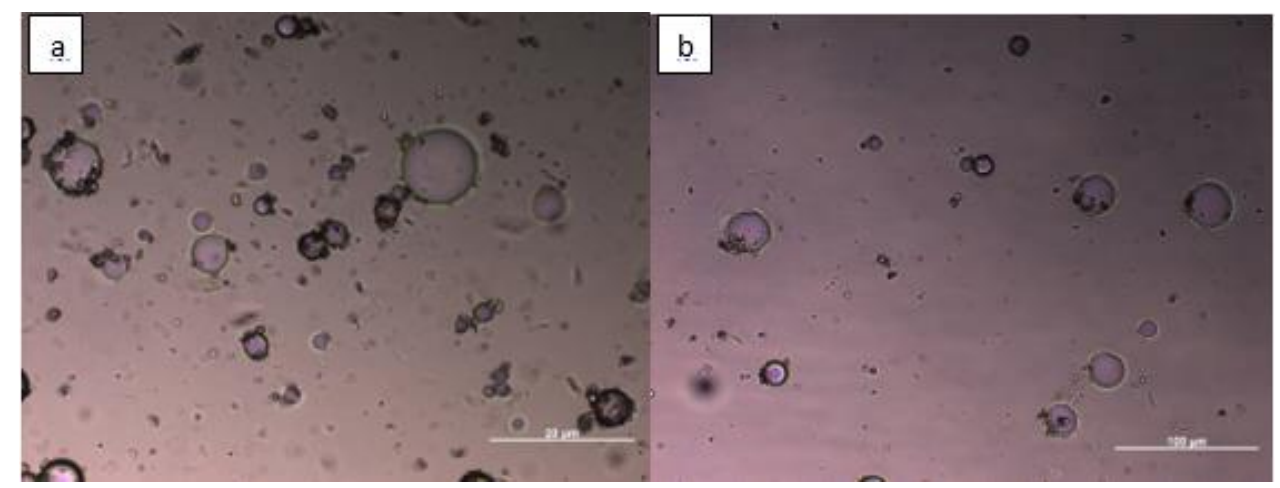

Figure4. Optical microscopy image of Pickering emulsions: a) with $3 \mathrm{~g} \mathrm{MgO}$ (scale bar $20 \mu \mathrm{m})$; b) with $2 \mathrm{~g}$ of $\mathrm{MgO}$ (scale bar $100 \mu \mathrm{m})$

Indeed, the most likely hypothesis would be the decrease in the diameter of the drops which is a function of the $\mathrm{MgO}$ content causing an increase in the interracial area.

This relation between the diameter and the quantity of particles is illustrated by the following formula [5]:

$$
D=\frac{6 \phi_{v} \quad V}{A}
$$

$\mathrm{D}$ is the diameter of the droplets, $\mathrm{V} / \mathrm{A}$ is the Interfacial air per unit volume, $\Phi \mathrm{v}$ is the fraction of the dispersed phase.

Similar results were obtained with hydrophobic silica [31]. Likewise, a high concentration of magnesium oxide promotes the increase in the viscosity of the continuous oily phase, which contributes to a better stability of the emulsions. A similar conclusion was found by Luis Torres and his collaborators with clay particles. However, other studies have shown that the excess of non-adsorbed particles contributes to the stabilization of emulsions by the formation of a three-dimensional network of flocculated particles. This improves the stability by interfering with the mutual contact of the droplets [32,33]. The amount of paracetamol incorporated influences the particle size of the aqueous droplets. Their sizes increase with the increase in the amount of paracetamol. The hydrophilic properties of paracetamol ensure that it remains in the aqueous phase of the emulsion, that is to say inside the droplets. This causes an increase in volume of the aqueous phase resulting in an increase in interfacial air. Frelichowska et al had shown that hydrophilic caffeine destabilized emulsions by increasing interfacial air [31,32].

\subsection{PH of Emulsions}

A basic character was observed for all of our emulsions. This basicity is more marked for emulsions containing $3 \mathrm{~g}$ of $\mathrm{MgO}$ than for emulsions containing $2 \mathrm{~g}$ of $\mathrm{MgO}$. An increase in $\mathrm{pH}$ was observed at 14 days on all emulsions. The figures 4 below show the evolution of the $\mathrm{pH}$ of our emulsions at day 1 , day 7 , day 14 , day 21 , day 28 . 

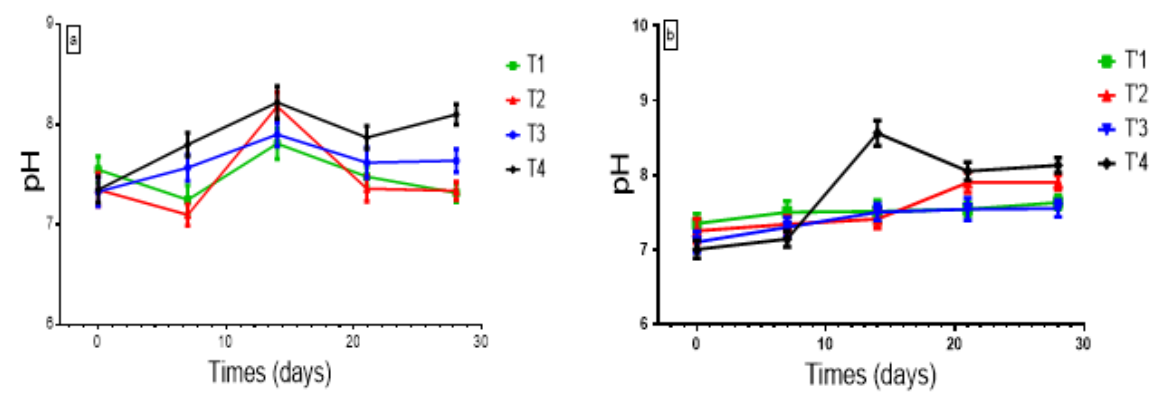

Figure4. $\mathrm{pH}$ of the formulations over time, (a) with $2 \mathrm{~g}$ of $\mathrm{MgO}$, (b) with $3 \mathrm{~g}$ of $\mathrm{MgO}$.

The $\mathrm{MgO}$ used is a powder with a strong basic character leading to the basicity $(\mathrm{pH}>7)$ of our emulsions giving them a better stability. YANG et al showed that a basic $\mathrm{pH}$ improves the stability of emulsions [33]. Indeed, for low $\mathrm{pH}$, the drops are large and not flocculated. Their interfaces are very covered by particles since the average coverage rate $\mathrm{C}$ is close to $90 \%$, a characteristic value of a compact twodimensional hexagonal stack.

\subsection{Conductivity}

The conductivity results are zero $0.00 \mathrm{mS} . \mathrm{cm}-1$ throughout the monitoring period of our emulsions. Studies have shown that the conductivity of the $\mathrm{W} / \mathrm{O}$ must be less than or equal to 0 . $01 \mathrm{mS} . \mathrm{cm}-1$ and the constant value of the conductivity in time is a decisive criterion of stability.

Indeed, the variation in conductivity is proportional to the variation of the external phase proportion when it is an $\mathrm{O} / \mathrm{W}$ emulsion and the conductivity hardly changes for changes in the proportion of an $\mathrm{W} / \mathrm{O}$ emulsion.

\subsection{Viscosity of the Emulsions}

The measurement of the viscosity gave us the results represented in the following figures 5 .
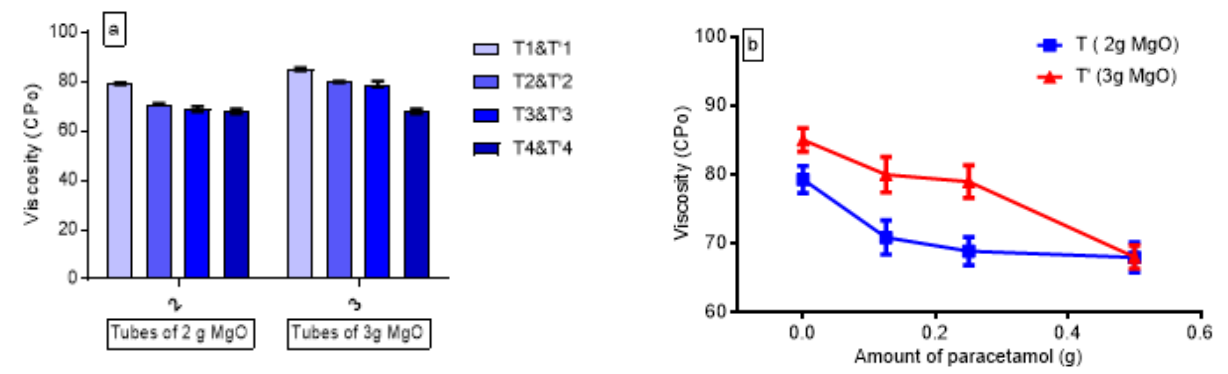

Figure5. Viscosity of the emulsions: (a) viscosity as a function of the amount of $\mathrm{MgO}$, (b) viscosity as a function of the amount of paracetamol incorporated

The viscosity of the emulsions was strongly influenced by the amount of magnesium oxide particles and paracetamol concentrations in the internal phase. We have found that a high concentration of magnesium oxide has led to an increase in the viscosity of the external phase of the emulsions. The tubes with $3 \mathrm{~g}$ of $\mathrm{MgO}$ have a much higher viscosity and are more stable.

\subsection{Coverage Rate}

It reflects the percentage of the surface area of the droplets formed by the stabilizing particles. It can be determined by the equation:

$$
C=\frac{m_{p} D}{4 C_{p} d_{p} V_{p}}
$$

$\mathrm{mp}=$ mass of the particles, $\mathrm{D}=$ size of the droplets, $\mathrm{Cp}=$ density of the particles, $\mathrm{dp}=$ diameter of the particles, $\mathrm{Vp}=$ volume of the dispersed phase

It is a key parameter for the stability of emulsions and the release of incorporated P.A. Indeed, the higher the coverage ratio, the more the interface is rigid, the less the system ages quickly, the less it 
Formulation and Evaluation of Water / Oil Pickering Emulsion Stabilized by Magnesium Oxide Particles Containing Paracetamol in the Internal Phase

easily releases PA Thus, there is an ideal coverage rate such that the system is stable and offers a kinetic of optimal release of the active ingredients incorporated. Table II shows the different coverage rates found. It intervenes as well in the stability of the emulsion as in the release of the incorporated active ingredients

Table6. Coverage Rates

\begin{tabular}{|l|l|l|l|l|l|l|l|l|}
\hline Tubes & T1 & T2 & T3 & T4 & T'1 & T'2 & T'3 & T'4 \\
\hline Coverage rate & 0,4576 & 0,4580 & 0,4596 & 0,4650 & 0,5761 & 0,5936 & 0,5971 & 0,6025 \\
\hline
\end{tabular}

The values obtained $(0.4<\mathrm{C}<0.65)$ show an increase in the coverage rate as a function of the number of particles in the preparation. The values of the coverage rate show that the droplets are stabilized by a monolayer or an interface not completely covered by the $\mathrm{MgO}$ particles at the interface. Aridity et al. have shown that droplets not completely covered by particles coalesce until the interface is completely covered [7]. The compact hexagonal stack (the densest) with two dimensions corresponds to $\mathrm{C}=0.9$. If the coverage ratio is equal to 0.9 then the particles are organized in the dense monolayer at the interface. If $\mathrm{C}>0.9$ of the multilayers or aggregates stabilize the drops.

\subsection{Encapsulation Efficiency (E.E)}

The following figure shows the appearance of the tubes after destabilization in the centrifuge. There is a total separation of the phases.

The dosage of the active ingredient (paracetamol) incorporated gave us the results represented on the following table III.

Table7. Initial concentration and found concentration

\begin{tabular}{|c|c|c|}
\hline incorporated Concentration $(\mathrm{g} / \mathrm{l})$ & found concentration $(\mathrm{g} / \mathrm{l})(2 \mathrm{~g} \mathrm{MgO})$ & found concentration $(\mathrm{g} / \mathrm{l})(3 \mathrm{~g} \mathrm{MgO})$ \\
\hline 0 & 0 & 0 \\
\hline 2 & 1,826 & 1,642 \\
\hline 4 & 3,662 & 3,349 \\
\hline 8 & 7,778 & 6,965 \\
\hline
\end{tabular}

By correlating the paracetamol concentrations in the formulation with the found concentration, the results are shown in the following figures 7 and 8.

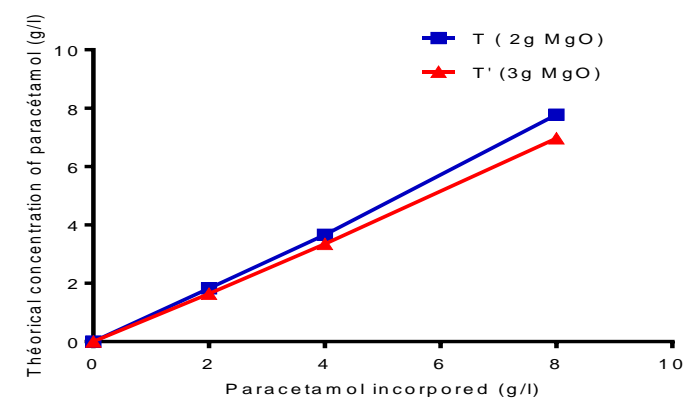

Figure7. Correlation between the concentration of paracetamol incorporated and that found after destabilization of the emulsion

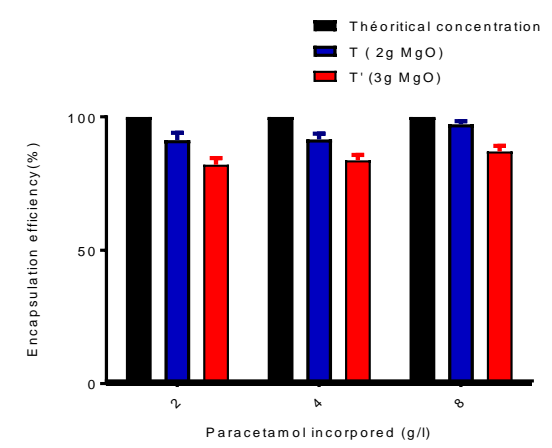

Figure8. Paracetamol Encapsulation Efficacy in Pickering Emulsions 
The use of UV - visible spectrophotometry can provide qualitative information to the analyst on the concentration of a substance in a Pickering emulsion after destabilization. Indeed, this technique finds applications in the pharmaceutical field in the qualitative and quantitative analysis of pure products or mixtures such as emulsions. The encapsulated active ingredient can be dispersed, dissolved or adsorbed on the surface of the particles. The large amounts of paracetamol found on all the formulations show that the active ingredient is dissolved largely in the dispersed phase. The encapsulated active ingredient can be dispersed, dissolved or adsorbed on the surface of the particles. The large amounts of paracetamol found on all the formulations show that the active ingredient is dissolved largely in the dispersed phase.

\section{CONCLUSION}

In view of the results obtained, we can say that we have been able to formulate a stable $\mathrm{W} / \mathrm{O}$ type Pickering emulsion containing paracetamol. Thus, these dispersed systems will protect an active ingredient in this formulation. They can increase solubility, therapeutic index by decreasing toxicity and increasing efficacy. In industry, Pickering emulsions have great potential for pharmaceutical and cosmetic formulation. This study will be supplemented by in vitro studies, and by release studies to obtain release profiles.

\section{REFERENCES}

[1] Pickering SU. 1907 Emulsions. J. Chem. Soc. Trans. 91, 2001-2021. (doi:10.1039/CT9079102001)

[2] Ramsden W. 1903 Separation of solids in the surface-layers of solutions and suspensions. Proc. R. Soc. Lond. 72, 156-164. (doi:10.1098/rspl.1903.0034)

[3] Scarlett AJ, Morgan WL, Hildebrand JH. 1926 Emulsification by solid powders. J. Phys. Chem. 31, 15661571. (doi:10.1021/j150280a010)

[4] Binks BP, Lumsdon SO. 2000 Influence of particle wettability on the type and stability of surfactant-free emulsions. Langmuir 16, 8622-8631. (doi:10.1021/la000189s)

[5] Abend S, Bonnke N, Gutschner U, Lagaly G. 1998 Stabilization of emulsions by heterocoagulation of clay minerals and layered double hydroxides. Colloid Polym. Sci. 276, 730-737. (doi:10.1007/s003960050303)

[6] Horozov TS, Binks BP. 2006 Particle-stabilized emulsions: a bilayer or abridging monolayer? Angew. Chem. Int. Ed. 45, 773-776. (doi:10.1002/anie.200503131)

[7] Arditty S, Whitby CP, Binks BP, Schmitt V, Leal-Calderon F. 2003 Some general features of limited coalescence in solid-stabilized emulsions. Eur. Phys. J. E 11, 273-281. (doi:10.1140/ epje/i2003-10018-6)

[8] Binks BP, Lumsdon SO. 1999 Stability of oil-in-water emulsions stabilised by silica particles. Phys. Chem. Chem. Phys. 1, 3007-3016. (doi:10.1039/a902209k)

[9] Colard CAL, Teixeira RFA, Bon SAF. 2010 Unraveling mechanistic events in solids-stabilized emulsion polymerization by monitoring the concentration of nanoparticles in the water phase. Langmuir 26, 79157921. (doi:10.1021/la904817f)

[10] Bon SAF, Colver PJ. 2007 Pickering miniemulsion polymerization using Laponite clay as a stabilizer. Langmuir 23, 8316-8322. (doi:10.1021/la701150q)

[11] Tsugita A, Takemoto S, Mori K, Yoneya T, Otani Y. 1983 Studies on O/W emulsions stabilized with insoluble montmorillonite-organic complexes. J. Colloid Interface Sci. 95, 551-560. (doi:10.1016/00219797(83)90214-X)

[12] Cui ZG, Shi KZ, Cui YZ, Binks BP. 2008 Double phase inversion of emulsions stabilized by a mixture of CaCO3 nanoparticles and sodium dodecyl sulphate. Colloids Surf. A 329, 67-74. (doi:10.1016/j.colsurfa .2008.06.049)

[13] Tambe DE, Sharma MM. 1993 Factors controlling the stability of colloid-stabilized emulsions. I. An experimental investigation. J. Colloid Interface Sci. 157, 244-253. (doi:10.1006/jcis.1993. 1182)

[14] Binks BP, Lumsdon SO. 2001 Pickering emulsions stabilized by monodisperse latex particles: effects of particle size. Langmuir 17, 4540-4547. (doi:10.1021/la0103822)

[15] Akartuna I, Tervoort E, Wong JCH, Studart AR, Gauckler LJ. 2009 Macroporous polymers from particlestabilized emulsions. Polymer 50, 3645-3651. (doi:10.1016/j.polymer.2009. 05.023)

[16] Oza KP, Frank SG. 1986 Microcrystalline cellulose stabilized emulsions. J. Dispersion Sci. Technol. 7, 543561. (doi:10.1080/01932698608943478) 
Formulation and Evaluation of Water / Oil Pickering Emulsion Stabilized by Magnesium Oxide Particles Containing Paracetamol in the Internal Phase

[17] Winuprasith T, Suphantharika M. 2013 Microfibrillated cellulose from mangosteen (Garcinia Mangostana L.) rind: preparation, characterization, and evaluation as an emulsion stabilizer. Food Hydrocolloids 32, 383-394. (doi:10.1016/j.foodhyd.2013.01.023)

[18] Winuprasith T, Suphantharika M. 2014 Properties and stability of oil-in-water emulsions stabilized by microfibrillated cellulose from mangosteen rind. Food Hydrocolloids 43, 690-699. (doi:10.1016/j.foo dhyd. 2014.07.027)

[19] Xhanari K, Syverud K, Chinga-Carrasco G, Paso K, Stenius P. 2011 Structure of nanofibrillated cellulose layers at the $\mathrm{O} / \mathrm{W}$ interface. J. Colloid Interface Sci. 356, 58-62. (doi:10.1016/j. jcis.2010.12.083)

[20] Ougiya H, Watanabe K, Morinaga Y, Yoshinaga F. 1997 Emulsion-stabilizing effect of bacterial cellulose. Biosci. Biotechnol. Biochem. 61, 1541-1545. (doi:10.1271/bbb.61.1541)

[21] Capron I, Cathala B. 2013 Surfactant-free high internal phase emulsions stabilized by cellulose nanocrystals. Biomacromolecules 14, 291-296. (doi:10.1021/bm301871k)

[22] Wen C, Yuan Q, Liang H, Vriesekoop F. 2014 Preparation and stabilization of Dlimonene Pickering emulsions by cellulose nanocrystals. Carbohydr. Polym. 112, 695-700. (doi:10.1016/j.carbpol.2014.06.051)

[23] Tasset S, Cathala B, Bizot H, Capron I. 2014 Versatile cellular foams derived from CNCstabilized Pickering emulsions. RSC Adv. 4, 893-898. (doi:10.1039/C3RA45883K)

[24] Lee K-Y, Blaker JJ, Murakami R, Heng JYY, Bismarck A. 2014 Phase behavior of medium and high internal phase water-in-oil emulsions stabilized solely by hydrophobized bacterial cellulose nanofibrils. Langmuir 30, 452-460. (doi:10.1021/la4032514)

[25] Cunha AG, Mougel J-B, Cathala B, Berglund LA, Capron I. 2014 Preparation of double Pickering emulsions stabilized by chemically tailored nanocelluloses. Langmuir 30, 9327-9335. (doi:10.1021/la5017577)

[26] Tang J, Lee MFX, Zhang W, Zhao B, Berry RM, Tam KC. 2014 Dual responsive Pickering emulsion stabilized by poly[2-(dimethylamino)ethyl methacrylate] grafted cellulose nanocrystals. Biomacromolecules 15, 3052-3060. (doi:10.1021/bm500663w)

[27] Zoppe JO, Venditti RA, Rojas OJ. 2012 Pickering emulsions stabilized by cellulose nanocrystals grafted with thermo-responsive polymer brushes. J. Colloid Interface Sci. 369, 202-209. (doi:10.1016/j.jcis.2011. 12.011)

[28] Kalashnikova I, Bizot H, Bertoncini P, Cathala B, Capron I. 2013 Cellulosic nanorods of various aspect ratios for oil in water Pickering emulsions. Soft Matter 9, 952-959. (doi:10.1039/C2SM26472B)

[29] Kalashnikova I, Bizot H, Cathala B, Capron I. 2012 Modulation of cellulose nanocrystals amphiphilic properties to stabilize oil/water interface. Biomacromolecules 13, 267-275. (doi:10.1021/bm201599j)

[30] Frelichowska j, Bolzinger m.a and Chevalier y. Effects of solid particle content on properties of o/w Pickering emulsions. Journal of Colloid and Interface Science 2010,351, p. 348-356.

[31] Frelichowska, J. Émulsions stabilisées par des particules solides : études physico-chimiques et évaluation pour l'application cutanée. Thèse pour obtenir le diplôme de Doctorat. Lyon : Université Claude Bernard Lyon 1, 2009, $\mathrm{n}^{\circ} 009,211 \mathrm{p}$.

[32] Pierat, N. Préparation d'émulsions par inversion de phase induite par agitation. Thèse pour obtenir le grade de Docteur en pharmacie. Nancy : Université Nancy1, 2010, 112p.

[33] Yang F, Liu S, Xu J, Lan Q, Wei F, Sun D. Pickering emulsion stabilized solely by layered double hydroxides particles: the effect of salt on emulsion formation and stability. J colloid interface science 2006, 302, p 309-169.

Citation: Sidy Mouhamed Dieng, et.al., (2019). Formulation and Evaluation of Water / Oil Pickering Emulsion Stabilized by Magnesium Oxide Particles Containing Paracetamol in the Internal Phase. ARC Journal of Pharmaceutical Sciences (AJPS), 5(1), pp.34-42. http://dx.doi.org/10.20431/2455-1538.0501004

Copyright: () 2019 Authors. This is an open-access article distributed under the terms of the Creative Commons Attribution License, which permits unrestricted use, distribution, and reproduction in any medium, provided the original author and source are credited. 